\title{
An Investigation of a Combined Thiourea and Hexamethylenetetramine as Inhibitors for Corrosion of N80 in 15\% HCl Solution: Electrochemical Experiments and Quantum Chemical Calculation
}

\author{
Jun Hu, ${ }^{1,2}$ Yun Wang, ${ }^{1}$ Lijun Yu, ${ }^{1}$ Yongqiang Zou, ${ }^{1}$ and Yuqi Wang ${ }^{1,2}$ \\ ${ }^{1}$ School of Chemical Engineering, Northwest University, No. 229 North Road of Taibai, Xi'an, Shaanxi 710069, China \\ ${ }^{2}$ Chemical Engineering Research Center of the Ministry of Education for Advanced Use Technology of Shanbei Energy, \\ Xian, Shaanxi 710069, China
}

Correspondence should be addressed to Jun Hu; hujun32456@163.com

Received 5 March 2015; Accepted 28 April 2015

Academic Editor: Ksenija Babic

Copyright (C) 2015 Jun Hu et al. This is an open access article distributed under the Creative Commons Attribution License, which permits unrestricted use, distribution, and reproduction in any medium, provided the original work is properly cited.

\begin{abstract}
The inhibition mechanism of thiourea (TU) and hexamethylenetetramine (HMTA) mixed in 15\% $\mathrm{HCl}$ solution on N80 surface was investigated by potentiodynamic polarization, electrochemical impedance spectroscopy measurements, and surface morphology analysis. Quantum chemical calculations and molecular dynamics simulations were performed to study the properties of TU and HMTA. The results showed that the inhibitors can form strong bonds and stable films on the surface, which inhibits the cathodic and anodic reactions in $\mathrm{HCl}$ solution and reduces the diffusion coefficients of corrosive particles.
\end{abstract}

\section{Introduction}

Fracturing technique is one of the main measures to increase oil production. Acidic solution is commonly used as fracturing fluid, which can decompose the big molecules into small molecules in order to discharge the oil from the crack $[1,2]$. However, acidic solution will make N80 carbon steel, the most used material in oil well, meet with corrosion easily [3].

The use of inhibitors is one of the most cost-effective and practical methods to protect metallic materials against corrosion in acidic medium $[4,5]$. Organic compounds, which generally contain $\mathrm{N}, \mathrm{O}, \mathrm{P}$, or $\mathrm{S}$ heteroatoms, are commonly used to control the corrosion damage of N80 [6-8]. Until now, there are a host of inhibitors that have been developed for N80, including acetylenic alcohols, aromatic aldehydes, alkenyl phenones, amines, amides, nitrogen containing heterocycles, nitriles, iminium salts, triazoles, pyridine and its derivatives or salts, quinoline derivatives, thiourea derivatives, thiosemicarbazide, thiocyanates, quaternary salts, and condensation products of carbonyls and amines $[9,10]$. Among these inhibitors, thiourea (TU) and its derivatives have aroused widespread concern due to its adsorption on various metal surfaces [11, 12]. A few studies investigated its potential use as an inhibitor for metal corrosion because their results manifested that the single TU molecule films contained a lot of defects. The stable adsorption layers of single TU molecules could only be formed on the surface of weakly negatively and positively charged electrodes [13-15]. Therefore, it might be a better choice to improve the inhibition efficiency by mixing another inhibitor to the solution at a proper proportion and overcome the disadvantages of a single inhibitor [16]. Recently, some studies focused on obtaining inhibitors with high inhibition efficiency in this way [17-19]. Hexamethylenetetramine (HMTA), which can also form a single molecular layer on metal surfaces by adsorption, is another shared inhibitor used in acidic environments [20]. So far, a few studies had been published on the inhibition effects of a solution containing a mixture of TU and HMTA. 
The objective of this paper is to investigate the inhibition action of TU and HMTA on surface of N80 steel in acidic medium by potentiodynamic polarization measurements, electrochemical impedance spectroscopy (EIS) measurements, and surface analysis and through structure analyses using quantum chemical simulation.

\section{Materials and Methods}

2.1. Materials. N80 carbon steel specimens were used with chemical composition (wt.\%): $0.42 \%$ C, $0.24 \%$ Si, $1.55 \%$ Mn, $0.012 \%$ P, $0.004 \%$ S, $0.051 \%$ Cr, $0.18 \%$ Mo, $0.005 \% \mathrm{Ni}$, $0.01 \% \mathrm{Ti}, 0.06 \% \mathrm{Cu}$, and Fe balance. The chemical structures and names of TU and HMTA are shown in Table 1. All specimens were manually mirror-polished by using grit $\mathrm{SiC}$ polishing papers with the grit size of 400, 800, and 1000, respectively. Thereafter, they were immersed in petroleum ether for 10 minutes, then washed thoroughly with bidistilled water, degreased with acetone, washed again with bidistilled water, and finally dried at room temperature.

For electrochemical measurements, specimens were cut into circular column with a dimension of $\Phi 14.5 \mathrm{~mm} \times 5 \mathrm{~mm}$ by using wire cutting method. Then, specimens were put into the sample support made by Teflon and only an active surface area of $10.5 \mathrm{~mm}$ was exposed to the solution for electrochemical measurement. The electrode was immersed for $24 \mathrm{~h}$ to retain stable before starting the measurements. The experiments were conducted in oxygen-free environment. The experimental temperatures were controlled at $25 \pm 1^{\circ} \mathrm{C}$ by a thermostat water bath during all experiments. The electrolyte solution was made from $\mathrm{HCl}$ and bidistilled water. The inhibitors were obtained from Sigma-Aldrich (USA) and used without any pretreatment.

2.2. Solution Preparation. The corrosion solution of $15 \%$ $\mathrm{HCl}$ was prepared from $37 \% \mathrm{HCl}$ using distilled water. The concentration range of TU varied from $4.0 \times 10^{-6}$ to $4.0 \times$ $10^{-3}$, and the concentration of HMTA was from 0.0001 to 0.1 .

2.3. Surface Analysis. Scanning electron microscope (SEM) studies and energy dispersive X-ray analysis (EDX) were performed to observe the morphology and discuss quantitative analysis of elements on the surface morphologies of N80 steel samples using VEGA3 TESCAN after immersions for $24 \mathrm{~h}$ in the absence and presence of optimum concentration of the inhibitor at $25 \pm 1^{\circ} \mathrm{C}$. The energy of the acceleration beam employed was $20 \mathrm{kV}$.

2.4. Electrochemical Measurements. The corrosion rate on the surface of N80 was evaluated by electrochemical measures in $15 \% \mathrm{HCl}$ at $25^{\circ} \mathrm{C}$. A conventional three-electrode system was used in all electrochemical measurements, which includes a working electrode, a saturated calomel electrode and platinum electrode. The electrochemical experiments were carried out with external potential. Electrochemical impedance spectroscopy (EIS) was performed at open circuit potential in the frequency range from $10 \mathrm{mHz}$ to $100 \mathrm{kHz}$ by superimposing alternating current signal of $10 \mathrm{mV}$ after
TABLE 1: Chemical structures and names of the studied thiourea and hexamethylenetetramine.

\begin{tabular}{lc}
\hline Structure & Name and abbreviation \\
\hline
\end{tabular}

immersion for $24 \mathrm{~h}$ in the corrosive solution. The polarization curves were recorded from $-250 \mathrm{mV}$ to $250 \mathrm{mV}$ (vs. SCE) with a scan rate of $0.1 \mathrm{mV} \mathrm{s}^{-1}$. In order to confirm the stability of the corrosion environment and the reproducibility of the experiments, each experiment was repeated three times.

2.5. Theoretical Calculations. Quantum chemical calculations can provide insight into the design of inhibitor systems with superior properties and elucidate the adsorption process at a molecular level [21-26]. The Dmol ${ }^{3+}$ and Discover modules of the Materials Studio 7.0 software (Accelrys Inc.) were employed for the quantum chemical calculations. The first indispensable step was to build and optimize TU and HMTA molecules and a 3-dimensional Fe (lll 111$)$ surface (because the main elements of N80 is Fe). Afterwards, a COMPASS force field was distributed on the structure. Then, the Amorphous Cell module was used to build the amorphous structure containing 100 molecules of corrosion inhibitors and 5 chloride ions and oxygen molecules. At last, the optimized Fe surface and the corrosion inhibitors were used to simulate $167.2 \mathrm{~nm} \times 167.2 \mathrm{~nm} \times 362.4 \mathrm{~nm}$ oxide film/corrosion inhibitor solution/vacuum layer structures.

During simulation, the position of the $\mathrm{Fe}$ atoms was fixed and the corrosive medium particles were modelled with the Discover module assuming a canonical ensemble (NVT) to simulate the diffusion through the corrosion inhibitor film. The simulation temperature was set at $25^{\circ} \mathrm{C}$ and both temperature and pressure were controlled by the AndersenBerendsen method. The distribution of the starting speed of the molecules was described by a Maxwell-Boltzmann distribution, assuming periodic boundary conditions and the equivalence of the time average and the ensemble average, for example, by using the Velocity Verlet algorithm to integrate Newton's equation of motion. Van der Waals and Coulomb interactions were simulated by using the charge group method. A truncation radius of $1.5 \mathrm{~nm}$ was selected (spline width: $0.10 \mathrm{~nm}$, buffer width: $0.05 \mathrm{~nm}$ ), and the truncation distance was corrected for intermolecular interactions according to the average density approximation method. A simulation time of $5000 \mathrm{fs}$ was chosen with a step length of $1.0 \mathrm{fs}$. The trajectory of a frame was recorded every 50 steps, resulting in a total output of 100 frames. 


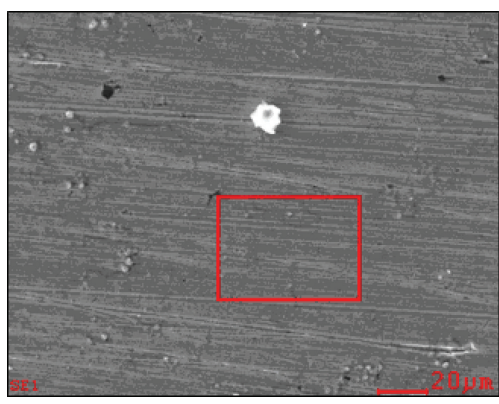

(a)

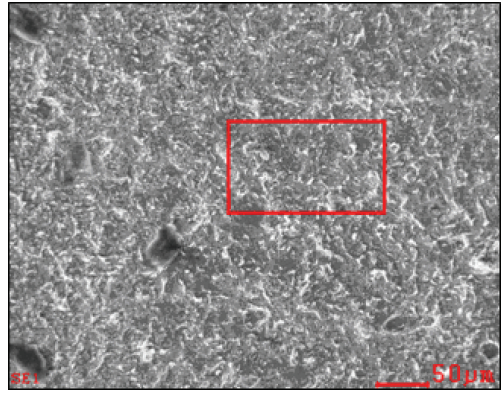

(c)

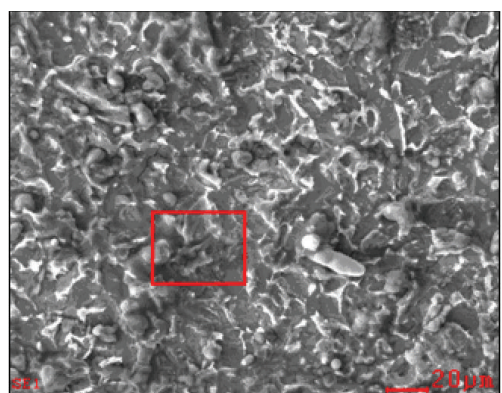

(e)

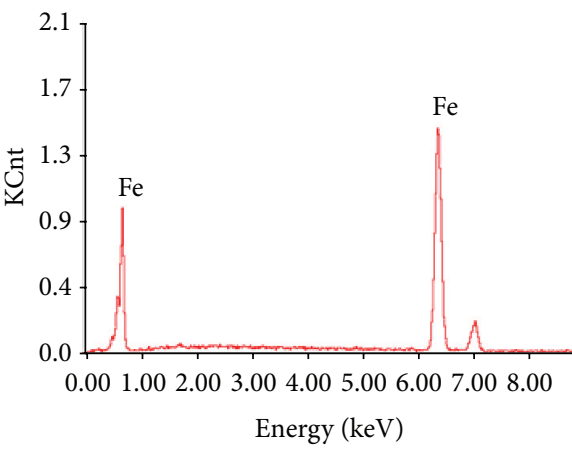

(b)

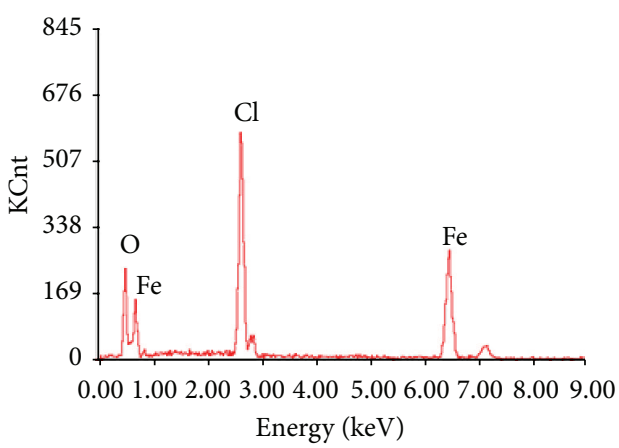

(d)

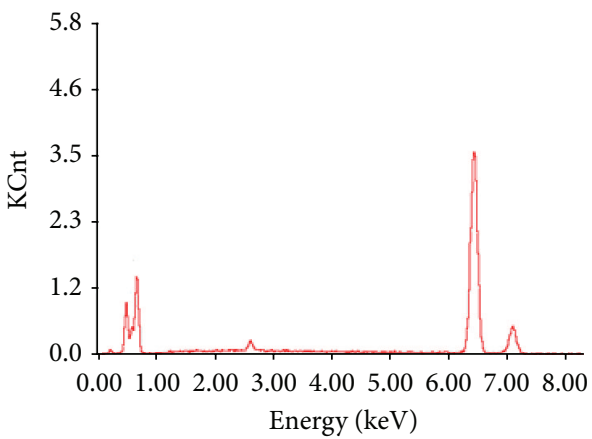

\begin{tabular}{lcc}
\hline Element & $(\mathrm{Wt} \%)$ & $(\mathrm{At} \%)$ \\
\hline CK & 01.92 & 07.19 \\
OK & 06.63 & 18.62 \\
ClK & 01.30 & 01.65 \\
FeK & 90.15 & 72.54 \\
Matrix & Correction & ZAF \\
\hline
\end{tabular}

(f)

\begin{tabular}{lcc}
\hline Element & $(\mathrm{Wt} \%)$ & $(\mathrm{At} \%)$ \\
\hline FeK & 100.00 & 100.00 \\
Matrix & Correction & ZAF \\
\hline
\end{tabular}

\begin{tabular}{lcc}
\hline Element & $(\mathrm{Wt} \%)$ & $(\mathrm{At} \%)$ \\
\hline OK & 20.77 & 42.86 \\
ClK & 30.30 & 28.21 \\
FeK & 48.94 & 28.93 \\
Matrix & Correction & ZAF \\
\hline
\end{tabular}


is dissolved and formed $\mathrm{FeCl}_{2}$; thus, these peaks represent the corrosion products formed on the surface. When TU and HMTA were added into hydrochloric acid medium (Figure 1(f)), the peaks of Fe become small in comparison to the samples without inhibitor molecule; at the same time, the intensity of $\mathrm{Cl}$ and $\mathrm{O}$ peaks are also dropped. The decrease of the $\mathrm{Fe}, \mathrm{Cl}$, and $\mathrm{O}$ peaks and also the appearance of $\mathrm{C}$ peak are indicative of the formation of adsorptive inhibitor film on the surface of N80. Consequently, the organic corrosion inhibitor film increases the transfer resistance of chloride ions from solution to metal surface and slows down the corrosion triggered by chloride ions.

\subsection{Electrochemical Experiments}

3.2.1. Potentiodynamic Polarization Measurements. The anodic and cathodic polarization curves for N80 measured after $24 \mathrm{~h}$ of immersion in $15 \% \mathrm{HCl}$ solution containing varying concentrations of TU and HMTA at $25 \pm 1^{\circ} \mathrm{C}$ are shown in Figure 2.

As it is seen in Figure 2, a lower current density was observed for cathodic curves in the presence of TU and HMTA in $\mathrm{HCl}$ solution. However, the anodic curves are nearly the same, thus pronouncing more cathodic reaction.

For the cathodic polarization curve, the $E$ versus $\log i$ is almost linear. In this case, the strong electric field intensity provides sufficient driving force for the diffusion of $\mathrm{H}^{+}$ions from the solution to the film. Furthermore, the diffusion of oxygen also exists. Therefore, the cathodic corrosion reaction in $15 \% \mathrm{HCl}$ solution is described by the following reaction (1):

$$
4 \mathrm{H}^{+}+\mathrm{O}_{2}+4 \mathrm{e}^{-} \longrightarrow 2 \mathrm{H}_{2} \mathrm{O}
$$

Adding the inhibitors strongly reduces the cathodic corrosion density compared to the pure $\mathrm{HCl}$ solution, indicating that the inhibitor can decrease the speed of reaction (1). Due to the adsorption of the inhibitor on the N80 surface, the active sites are covered, and the adsorbed inhibitor film will induce an extra energy barrier for the diffusion of $\mathrm{H}^{+}$. Furthermore, the film can also reduce the diffusion of oxygen. In summary, these factors restrain the cathodic corrosion process.

Anodic polarization lines show the dissolution of Fe into $\mathrm{Fe}^{2+}$ and proceed in the form of corrosion [27] and the diffusion of $\mathrm{Fe}^{2+}$ from the outer Helmholtz plane into the bulk solution [28]. After adding the inhibitors, the slopes of the anodic polarization lines nearly unchanged, indicating that the presence of the inhibitors in the solution has little effect on the dissolution rate of $\mathrm{N} 80$.

The corresponding corrosion potential $\left(E_{\text {corr }}\right)$, corrosion current density $\left(i_{\text {corr }}\right)$, anodic Tafel slopes $\left(\beta_{a}\right)$, and cathodic Tafel slopes $\left(\beta_{c}\right)$ are listed in Table 2, and the values were calculated using (2)-(4). Subsequently, the inhibition effects were then calculated using (5). One can see the following:

$$
\begin{aligned}
& \beta_{a}=\frac{R T}{(1-\alpha) n F}, \\
& \beta_{c}=\frac{R T}{\alpha n F},
\end{aligned}
$$

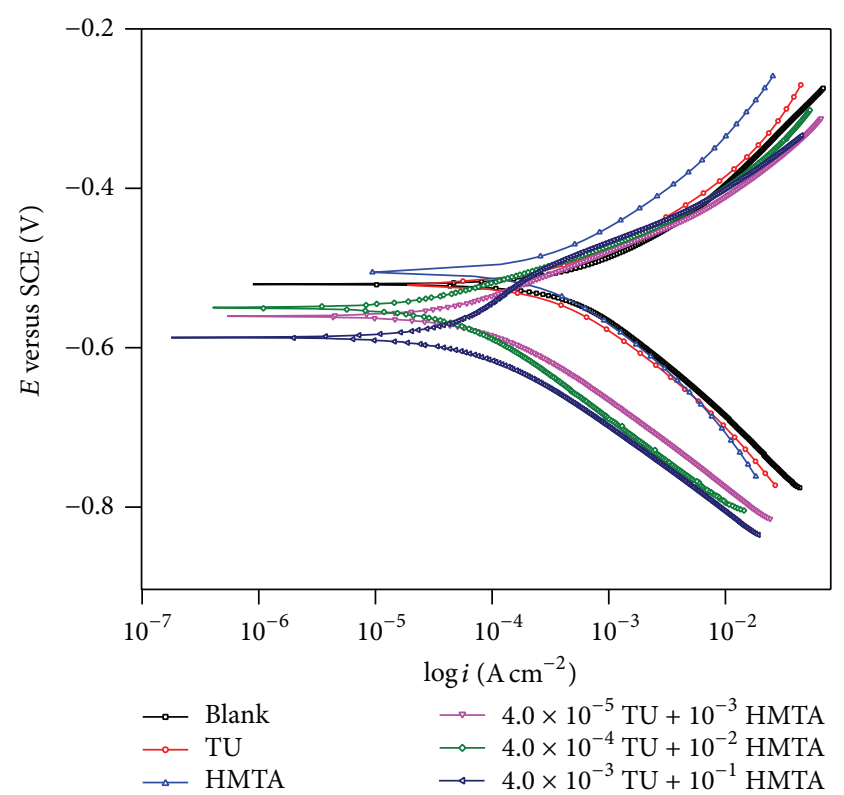

FIgURE 2: Anodic and cathodic polarization curves for N80 in 15\% $\mathrm{HCl}$ in the absence and presence of various concentrations of TU and HMTA derivatives at $25 \pm 1^{\circ} \mathrm{C}$.

$$
\begin{aligned}
i & =i_{\text {corr }}\left(\exp \left(\frac{\Delta E}{\beta_{a}}\right)-\exp \left(-\frac{\Delta E}{\beta_{c}}\right)\right), \\
\eta \% & =\frac{i_{\text {corr }}^{*}-i_{\text {corr }}}{i_{\text {corr }}^{*}} \times 100 .
\end{aligned}
$$

Table 2 shows that the values of $\beta_{a}$ and $\beta_{c}$ for the pure $\mathrm{HCl}$ solution are extremely larger than other cases, indicating that passive films were formed on the N80 surface after adding the inhibitors. After adding the inhibitors, the values for $\beta_{a}$ and $\beta_{c}$ did not significantly change, which means that the anodic and cathodic reactions were similar.

The corrosion current density is one of the most crucial indicators for the evaluation of the corrosion resistance. The corrosion current density $\left(i_{\text {corr }}\right)$ on the N80 electrode in $15 \% \mathrm{HCl}$ solution in the absence of inhibitor is $6.467 \times$ $10^{-3} \mathrm{~A} \cdot \mathrm{cm}^{-2}$, and the corrosion potential is $-0.519 \mathrm{~V}(\mathrm{SCE})$. In general, the corresponding corrosion potential is decreased after adding inhibitors; this mainly attributes to the restrain of cathodic reactions. The corrosion current densities $i_{\text {corr }}$ decrease with the increasing inhibitor concentration. The lowest dissolution current density on the N80 occurs at the highest inhibitor concentration. From Table 2, when the TU was added into $\mathrm{HCl}$ solution, the value of $i_{\text {corr }}$ is lower than that in $\mathrm{HCl}$ solution obviously. Thus, the efficiency calculated by (5) is $94.57 \%$. It indicates that TU was adsorbed in the active site of the electrode surface, and the rate of corrosion on the surface of N80 decreased. In addition, HMTA also has a high efficiency for $\mathrm{N} 80$ in $\mathrm{HCl}$ solution by the results. When the TU and HMTA were added to $\mathrm{HCl}$ solution, the higher the concentration of TU and HMTA is, the lower the value of $i_{\text {corr }}$ is. The corrosion potential shifts to negative direction. The value of $i_{\text {corr }}$ is $0.287 \times 10^{-3} \mathrm{~A} \cdot \mathrm{cm}^{-2}$ in a solution containing $0.004 \mathrm{M}$ TU and 0.1 M HMTA, which is 
TABLE 2: Corrosion kinetics parameters of N80 in 15\% $\mathrm{HCl}$ solution with different corrosion inhibitor.

\begin{tabular}{|c|c|c|c|c|c|}
\hline Sample (M) & $\beta_{a}(\mathrm{mV})$ & $\beta_{c}(\mathrm{mV})$ & $E_{\text {corr }}(\mathrm{V})$ & $I_{\text {corr }} \times 10^{-3}\left(\mathrm{~A} \cdot \mathrm{cm}^{-2}\right)$ & $\eta(\%)$ \\
\hline $15 \% \mathrm{HCl}$ & 118.37 & 146.65 & -0.519 & 6.467 & - \\
\hline $0.1 \mathrm{M} \mathrm{TU}$ & 95.52 & 124.73 & -0.519 & 0.351 & 94.57 \\
\hline $4.0 \times 10^{-3}$ M HMTA & 110.89 & 131.9 & -0.503 & 0.322 & 95.02 \\
\hline $15 \%+4.0 \times 10^{-5} \mathrm{M} \mathrm{TU}+0.001 \mathrm{M}$ HMTA & 81.04 & 103.49 & -0.559 & 0.637 & 90.14 \\
\hline $15 \%+4.0 \times 10^{-4} \mathrm{M}$ TU $+0.01 \mathrm{M}$ HMTA & 77.38 & 111.06 & -0.548 & 0.419 & 93.52 \\
\hline $15 \%+4.0 \times 10^{-3} \mathrm{M}$ TU $+0.1 \mathrm{M}$ HMTA & 82.62 & 88.85 & -0.584 & 0.287 & 95.56 \\
\hline
\end{tabular}

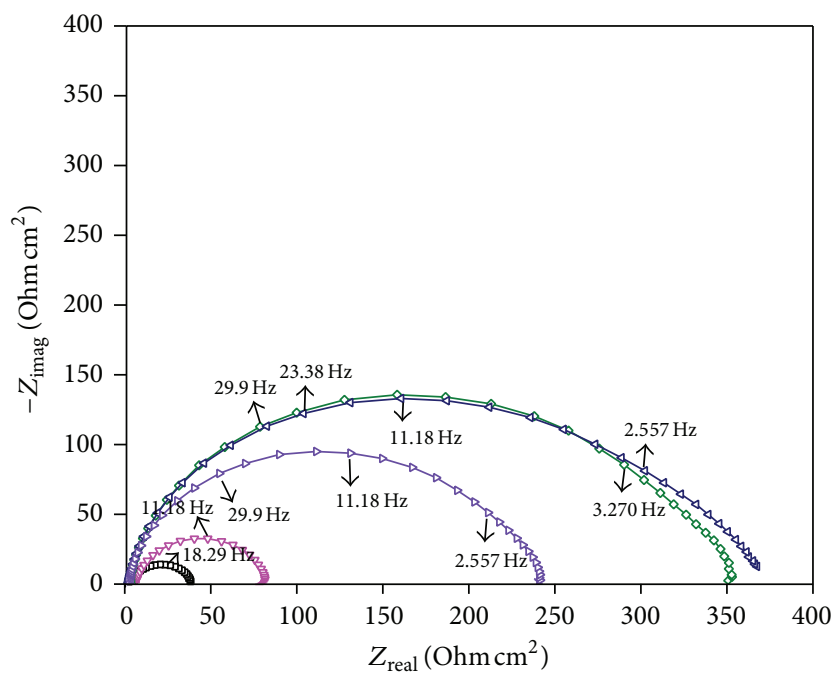

$$
\begin{aligned}
& \multimap \text { Blank } \multimap 4.0 \times 10^{-4} \mathrm{TU}+10^{-2} \mathrm{HMTA} \\
& \multimap 4.0 \times 10^{-6} \mathrm{TU}+10^{-4} \mathrm{HMTA} \rightarrow 4.0 \times 10^{-3} \mathrm{TU}+10^{-1} \mathrm{HMTA} \\
& \rightarrow 4.0 \times 10^{-5} \mathrm{TU}+10^{-3} \text { HMTA }
\end{aligned}
$$

(a)

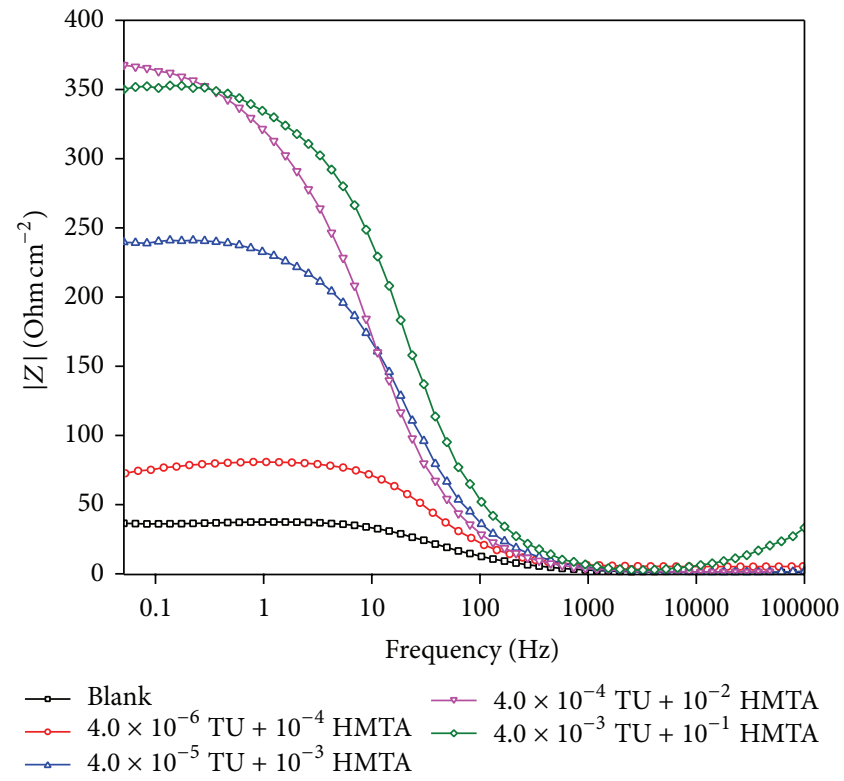

(b)

Figure 3: Electrochemical impedance spectroscopy diagrams for $\mathrm{N} 80$ electrode in $15 \% \mathrm{HCl}$ solution in the absence and presence of various concentrations of a mix of both inhibitors, TU and HMTA, at $25 \pm 1^{\circ} \mathrm{C}$ : (a) Nyquist plots, (b) Bode plots.

smaller compared with the inhibitors alone. This suggests that adding TU and HMTA have synergistic effect. The highest observed inhibition efficiency was $95.56 \%$, the decrease in the current density is attributed to the adsorption of the inhibitor molecules on the N80 surface, forming a protective layer and blocking the active sites on the metal surface.

\subsubsection{Electrochemical Impedance Spectroscopy (EIS) Measure-} ments. To get further information concerning the inhibition process, EIS measurements on the N80 electrode were performed. EIS is capable of in situ and nondestructively probing relaxation phenomenon over a wide frequency range [29]. Nyquist and Bode plots of $\mathrm{N} 80$ electrode in $15 \% \mathrm{HCl}$ are shown in Figure 3.

The Nyquist plots obtained for $\mathrm{N} 80$ in $15 \% \mathrm{HCl}$ in the absence and presence of various concentrations of the TU and HMTA are shown in Figure 3(a). These plots were characterized by a semicircular capacitive loop at high frequency. The Nyquist plot contains a capacitive loop in high frequency region, the center of capacitive loop lies under the real axis, which is related to the roughness, inhomogeneity of the solid surfaces, or adsorption of inhibitors. It is worth noting that the high frequency region should mainly display quick responses of the inhibitor film $[30,31]$. The capacitive loop is linked to the charge transfer resistance of the inhibitor film. Figure 3(a) shows that the capacitive loops become stronger with an increase of the inhibitor concentration, mainly due to the absorption of the inhibitor at the active sites on the N80 surface and the formation of a continuous film, exhibiting a barrier effect. It would effectively protect the metal from aggressive attack by the solution, which increases the charge transfer resistance.

The $\log |Z|-\log f$ plot in the medium frequency range is an oblique line, indicating that the system has a predominant capacitive behaviour. For frequencies higher than $10^{3} \mathrm{~Hz}$, the values of $|Z|$ in the solutions containing inhibitors are about $1-3 \Omega \cdot \mathrm{cm}^{-2}$ except the experiment that contains $0.004 \mathrm{M}$ TU and $0.1 \mathrm{M}$ HMTA. This shows that only the resistance of the solution was detected in this region. It might show some rearrangements or a partial desorption of the inhibitor. In $0.004 \mathrm{M}$ TU and 0.1 M HMTA, the values of $|Z|$ gradually increase from $2 \Omega \cdot \mathrm{cm}^{-2}$ to $33 \Omega \cdot \mathrm{cm}^{-2}$, indicating that there are strong interactions between metal surface and inhibitor and the desorption process is arduous to occur. 
TABLE 3: Electrochemical parameters calculated from EIS measurements on N80 electrode in $15 \% \mathrm{HCl}$ solution for different corrosion inhibitor concentrations at $25 \pm 1^{\circ} \mathrm{C}$.

\begin{tabular}{lcccccccc}
\hline Sample $(\mathrm{M})$ & $R_{\mathrm{s}}\left(\Omega \mathrm{cm}^{2}\right)$ & $Q_{1}\left(\mathrm{~S} \mathrm{~s}^{n} \mathrm{~cm}^{-2}\right)$ & $n_{1}(0<n<1)$ & $R_{f}\left(\Omega \mathrm{cm}^{2}\right)$ & $Q_{2}\left(\mathrm{~S} \mathrm{~s}^{n} \mathrm{~cm}^{-2}\right)$ & $n_{2}(0<n<1)$ & $R_{\mathrm{ct}}\left(\Omega \mathrm{cm}^{2}\right)$ & $\theta$ \\
\hline $\mathrm{HCl}$ & 0.9203 & 0.0002918 & 0.9054 & 32.25 & 0.0003987 & 0.8785 & 3.943 \\
0.0001 & 5.235 & 0.0004901 & 0.8346 & 11.29 & 0.0001136 & 1 & 59.84 & 0.934 \\
0.001 & 1.175 & 0.0000483 & 0.929 & 239.5 & 0.0005603 & 0.9017 & 123.3 & 0.968 \\
0.01 & 1.307 & 0.0003884 & 0.9332 & 94.47 & 0.0000725 & 0.9408 & 143.6 & 0.973 \\
0.1 & 1.884 & 0.0003417 & 0.9068 & 136.4 & 0.00004803 & 0.9515 & 210.4 & 0.981 \\
\hline
\end{tabular}

The equivalent circuit, shown in Figure 4, was used to fit the EIS data.

In the equivalent circuit, $R_{s}$ is the solution resistance; $R_{\mathrm{ct}}$ is the charge transfer resistance; $\mathrm{CPE}_{\mathrm{dl}}$ and $\mathrm{CPE} \mathrm{dl}_{2}$ denote the constant phase elements representing the capacitance of the electric double layer and inhibitor film, respectively; and $R_{f}$ denotes the resistance of inhibitor film [32]. Table 3 lists the fitting parameters obtained by using corresponding equivalent circuits.

According to Table 3, the changes of $R_{s}$ are small. Based on the definition of the capacitance, the changes of $\mathrm{CPE}_{\mathrm{dl}}$ can be mainly attributed to $\varepsilon$ (the relative dielectric constant) and the thickness of the film. In the pure $\mathrm{HCl}$ solution, the value of $\varepsilon$ is similar to the value of the dielectric constant for water. After adding the inhibitors, the value of $\varepsilon$ is equal to the value of the dielectric constant for the inhibitors due to the absorption of the inhibitors on the N80 surface; thus, $\varepsilon$ will decrease after adsorption. At the same time, the thickness of the film will increase due to adsorption of the inhibitors on the N80 surface. The combination of these factors is leading to a decrease of $Q_{2}$. Because $n$ is related to the roughness and the heterogeneity of the surface, $n=1$ stands for an ideal capacitance [33], and the values of $n$ also verify these results. The $n_{1}$ increases gradually along with the concentration of inhibitors, which indicates that the film became integrated gradually. The increase of $R_{\mathrm{ct}}$ is suggestive of the increase of charge transfer resistance of the inhibitor film gradually, which is attributed to the formation of protective film on the metal/solution interface.

Kramers-Kronig (K-K) transformation is often used as an independent check for the validity of the impedance data. Most frequently, when applied to EIS data, the transformation equations are written as follows [34]:

$$
\begin{aligned}
& Z^{\prime}(\omega)=Z^{\prime}(\infty)+\frac{2}{\pi} \int_{0}^{\infty} \frac{x Z^{\prime \prime}(x)-\omega Z^{\prime \prime}(\omega)}{x^{2}-\omega^{2}} d x \\
& Z^{\prime}(\omega)=Z^{\prime}(0)+\frac{2 \omega}{\pi} \int_{0}^{\infty} \frac{(\omega / x) Z^{\prime \prime}(x)-Z^{\prime \prime}(\omega)}{x^{2}-\omega^{2}} d x \\
& Z^{\prime \prime}(\omega)=-\frac{2 \omega}{\pi} \int_{0}^{\infty} \frac{Z^{\prime}(x)-Z^{\prime}(\omega)}{x^{2}-\omega^{2}} d x
\end{aligned}
$$

where $\omega$ is the transformation frequency, $x$ is the integration frequency, and $Z^{\prime}$ and $Z^{\prime \prime}$ denote the real and imaginary components of the impedance, respectively. Equations (1) and (2) provide the imaginary axis-to-real axis transformations,

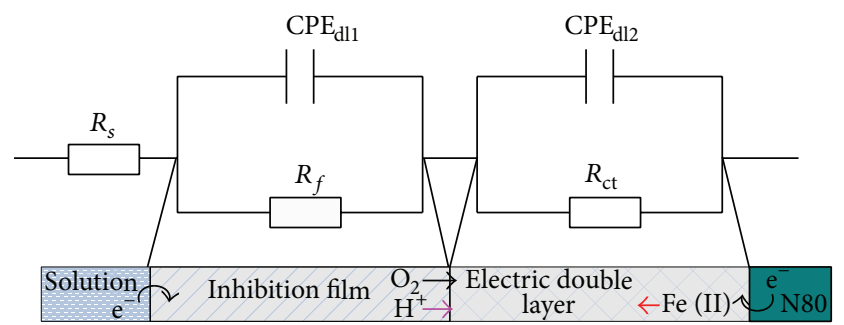

FIGURE 4: The equivalent circuit used to model the electrochemical impedance spectroscopy data at open circuit potential at $25 \pm 1^{\circ} \mathrm{C}$.

while (3) yields the real axis-to-imaginary axis transformation. The measurement and fitting error of the impedance are manifested in Figure 5 for five different etching solutions.

The chi-square errors for each of the impedance spectroscopy data set are $2.29 \times 10^{-3}, 3.97 \times 10^{-3}, 2.11 \times 10^{-3}$, $6.37 \times 10^{-3}$, and $1.72 \times 10^{-3}$, respectively, for the different solutions. As shown in Figure 5, the relative errors between the transformation data and the experimental data are in the range of $10 \%$ except at some points. Since some random errors of the system are inevitable to occur, the experimental data and the fitting result can be considered to be in perfect agreement. Therefore, the quintessential random distribution of the errors obtained in the fitting data indicates that the $\mathrm{K}$ $\mathrm{K}$ transformations are consistent with the experimental data and the equivalent circuit is a suitable tool for the analysis.

3.3. Adsorption Isotherm. The surface coverage is a paramount parameter for the evaluation of the quality of the corrosion inhibitor film. The surface coverage $\theta$ can be used to calculate the following formula proposed by Shu et al. [35]:

$$
\theta=1-\frac{R_{\mathrm{ct}}^{0}}{R_{\mathrm{ct}}}
$$

where $R_{\mathrm{ct}}^{o}$ and $R_{\mathrm{ct}}$ are the charge transfer resistance for N80 in the absence and presence of the inhibitor, respectively. Based on the calculations, the highest obtained value for $\theta$ is 0.981 .

The adsorption of organic molecules provides information concerning the interaction among the adsorbed molecules themselves as well as their interaction with the electrode surface [36]. The most frequently used adsorption isotherms are the Langmuir, Temkin, and Freundlich $[37,38]$. The experimental data was fitted by using these adsorption 


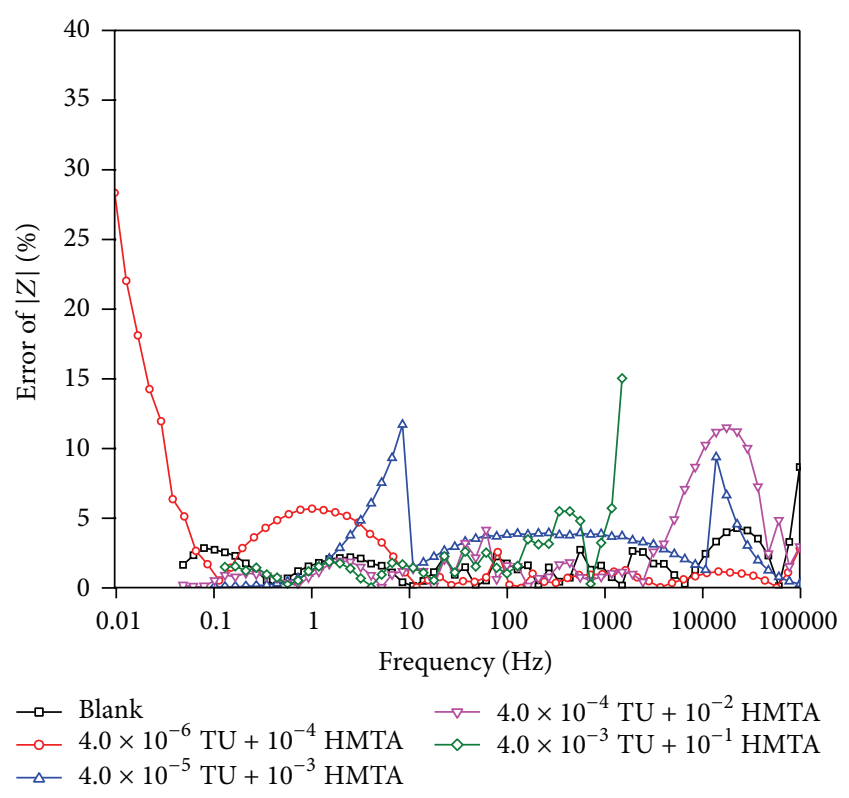

Figure 5: Measurement and fitting error of $|Z|$ for N80 after exposure to four different solutions at open circuit potential and 25 $\pm 1^{\circ} \mathrm{C}$.

isotherms and it was found that Langmuir absorption provided the best agreement with the experimental results. The Langmuir adsorption isotherm can be expressed as follows:

$$
\frac{C_{\text {inh }}}{\theta}=C_{\text {inh }}+\frac{1}{K},
$$

where $K$ is the constant of the adsorption equilibrium including the adsorption-free energy and $C$ is the inhibitor concentration [39]. The corresponding plot for the Langmuir adsorption isotherm is demonstrated in Figure 6.

The value of $K$ is related to the standard-free energy of adsorption, $\Delta G_{\mathrm{ads}}^{0}$, calculated by as follows [40-42]:

$$
\Delta G_{\mathrm{ads}}^{0}=-R T \ln (55.5 K),
$$

where $R$ is the gas constant and $T$ is the absolute temperature.

In this case, the value of $\Delta G_{\text {ads }}^{0}$ is $-35.50 \mathrm{~kJ} \cdot \mathrm{mol}^{-1}$, which suggests that the adsorption mechanism of TU and HMTA on N80 surface mainly involves chemisorption [43, 44]. At first, water molecules are adsorbed on the N80 surface and the adsorption of the inhibitors occurs due to electrostatic interaction, followed by the removal of water molecules from the surface. Afterwards, chemical interactions will occur between the metal surface and the inhibitors due to the short distance. Because chemisorptions yield more stable bonds than physisorption, the formed film is stable.

3.4. Quantum Chemical Calculations. The electronic parameters give the information concerning the interaction between inhibitor and metal surface. Quantum chemical calculations are the most used method to understand electronic distribution of a molecule [45-47]. Some properties of the inhibitors calculated by quantum chemical calculations are presented as shown in Figure 7.

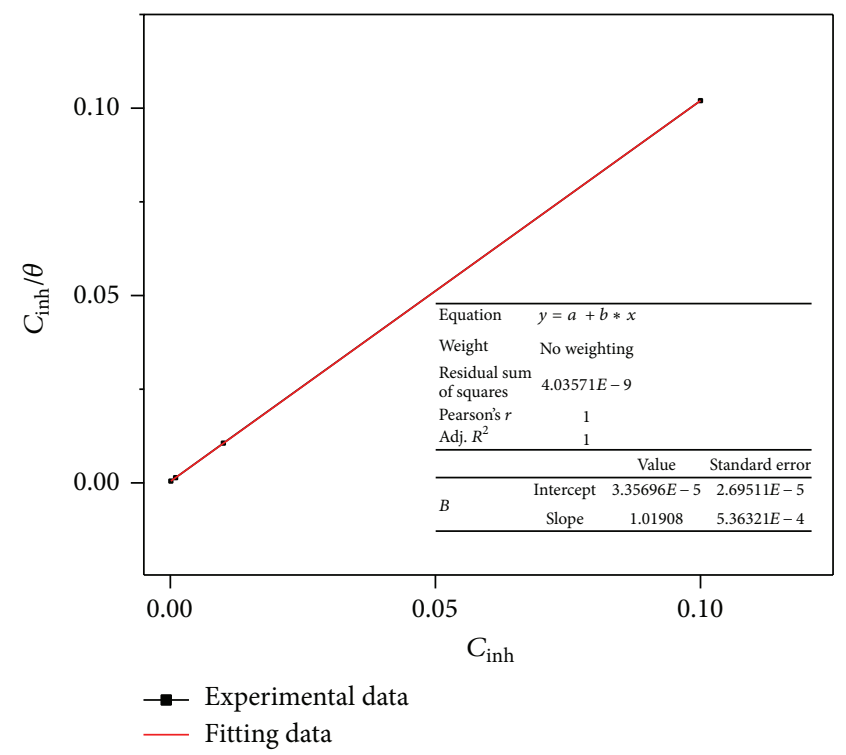

FIGURE 6: Langmuir adsorption isotherm model for $\mathrm{N} 80$ in $15 \% \mathrm{HCl}$ containing a mix of the inhibitors TU + HMTA at $25 \pm 1^{\circ} \mathrm{C}$.

Figure 7 shows the optimized geometries and Mulliken atomic charges of TU and HMTA. Usually, the negative atomic charges are the adsorbed center because the electrons around the negative atomic can easily move to the unoccupied orbital of the metal/metal oxide. Figure 7 manifests that the most negative atomic charges happen in the $\mathrm{N}$ atomic for every inhibitor. The $\mathrm{N}$ atomic charges are -0.829 and -0.305 for TU and HMTA, respectively. This indicates that $\mathrm{N}$ is easily absorbed into N80 surface than other atoms. The map of the highest occupied molecular orbital (HOMO) and the lowest unoccupied molecular orbital (LUMO) also verify that the heterocyclic ring has high tendency to donate electrons to the metal surface. The quantitative results of quantum chemical parameters are calculated as shown in Table 4.

According to the frontier molecular orbital theory of chemical reactivity by Fukui, most of the electron transition will happen at the frontier orbitals, named HOMO and LUMO of reacting species. The energy of HOMO $\left(E_{H}\right)$ is directly related to the ionization potential and characterizes the susceptibility of the molecule toward attack by electrophiles; it is a measure of electron donating ability of inhibitors and explains the adsorption on N80 surfaces by a way of delocalized lone pair of electrons. The $E_{H}$ for HMTA is $-477.6 \mathrm{~kJ} \cdot \mathrm{mol}^{-1}$ and TU $-483.6 \mathrm{~kJ} \cdot \mathrm{mol}^{-1}$. This indicates the bond of HMTA formed on the surface of N80 is stronger than that of TU. The energy of LUMO $\left(E_{L}\right)$, which stands for the ability of electron receiving tendency, is directly related to the electron affinity and characterizes the susceptibility of the molecule toward attack by nucleophiles [48, 49]. The lower the values of $E_{L}$ are, the stronger the electron accepting abilities of the molecules are. The LUMO of N80 can accept the electron of inhibitors in the HOMO. Based on these parameters, the calculated difference $\left(\Delta E=E_{L}-E_{H}\right)$ demonstrates inherent electron donating ability and measures the interaction of the inhibitor molecule with the N80 
TABLE 4: Quantum chemical parameters derived for different inhibitors.

\begin{tabular}{|c|c|c|c|c|c|c|c|c|c|c|}
\hline Inhibitors & $\begin{array}{c}\text { Total energy } \\
\left(\mathrm{kJ} \mathrm{mol}{ }^{-1}\right)\end{array}$ & $\begin{array}{c}\text { HOMO } \\
\left(\mathrm{kJ} \mathrm{mol}^{-1}\right)\end{array}$ & $\begin{array}{c}\text { LUMO } \\
\left(\mathrm{kJ} \mathrm{mol}^{-1}\right)\end{array}$ & $\begin{array}{c}\Delta E \\
\left(\mathrm{~kJ} \mathrm{~mol}^{-1}\right)\end{array}$ & $\begin{array}{c}\mu \\
\text { (debye) }\end{array}$ & $\begin{array}{c}I \\
\left(\mathrm{~kJ} \mathrm{~mol}^{-1}\right) \\
\end{array}$ & $\begin{array}{c}A \\
\left(\mathrm{~kJ} \mathrm{~mol}^{-1}\right)\end{array}$ & $\chi$ & $\begin{array}{c}\eta \\
\left(\mathrm{kJ} \mathrm{mol}^{-1}\right)\end{array}$ & $\Delta N$ \\
\hline $\mathrm{TU}$ & $1.47 \times 10^{6}$ & -483.6 & -51.2 & 432.5 & 3.545 & 483.6 & 51.2 & 267.4 & 216.3 & 0.45 \\
\hline HMTA & $-1.29 \times 10^{6}$ & -477.6 & 98.3 & 575.9 & 0.014 & 477.6 & -98.3 & 189.7 & 287.9 & 0.47 \\
\hline
\end{tabular}

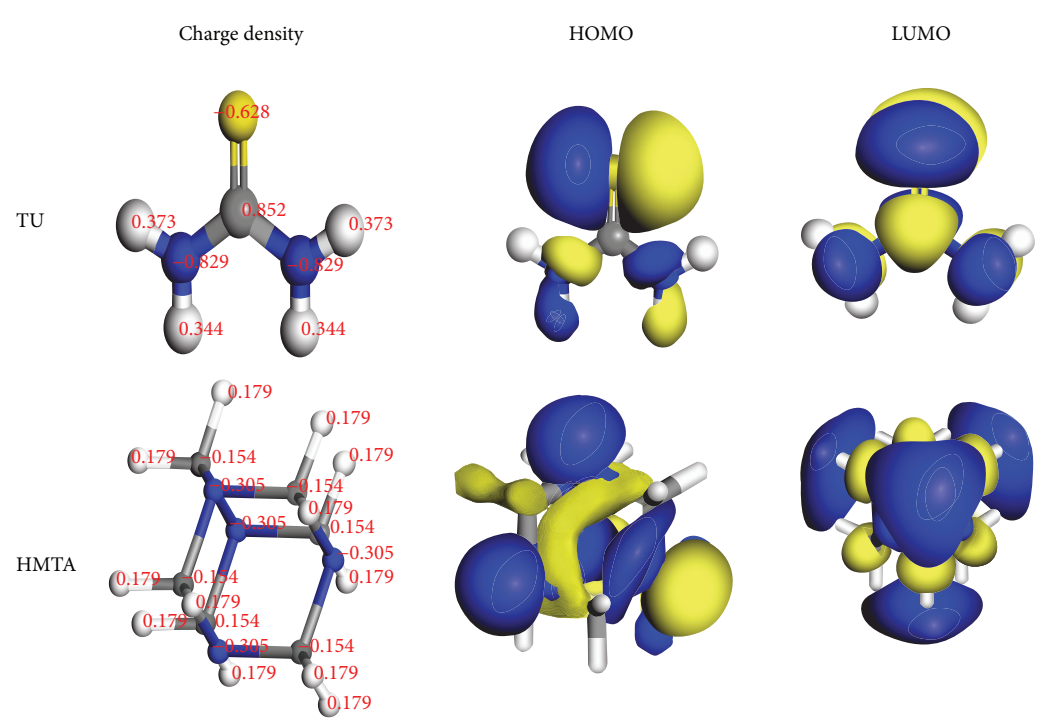

FIgURE 7: The optimized structures and molecular orbital plots for inhibitors.

surface. The $\Delta E$ for TU and HMTA are $432.5 \mathrm{~kJ} \cdot \mathrm{mol}^{-1}$ and $575.9 \mathrm{~kJ} \cdot \mathrm{mol}^{-1}$, respectively. Because the molecules with small $\Delta E$ value have greater reactivity than molecules that have large $\Delta E$ value, it can be concluded that TU have more affinity on N80 surface.

The effect of dipole moment, $\mu$, of inhibitor creates a significant static electric field that leads to upward/downward bending of surface energy. From Table 4, it can be seen that the dipole moment of TU is 3.545 debyes. So, there are polar molecules. It can be interpreted that TU will have interaction with other polar molecules in solution such as water and $\mathrm{H}^{+}$ molecule. Experimental results verify the simulated results [50]. For TU, it has great interaction with water in the solution. Accordingly, the TU film will have an ocean of defects.

Some other parameters such as $\chi, \eta$, and $\Delta N$ are also calculated. Based on Hartree-Fock theorem, the ionization potential $(I)$ and the electron affinity $(A)$ are given by

$$
\begin{aligned}
& I=-E_{\text {HOMO }} \\
& A=-E_{\text {LUMO }}
\end{aligned}
$$

For absolute electronegativity, $\chi$, and global hardness, $\eta$, their operational and approximate definitions are as follows:

$$
\begin{aligned}
& \chi=\frac{I+A}{2}, \\
& \eta=\frac{I-A}{2} .
\end{aligned}
$$

Two systems, N80 and inhibitor, are brought together, and electrons will flow from lower $\chi$ (inhibitor) to higher $\chi$ (N80), until the chemical potentials become equal. The fraction of electrons transfer, $\Delta N$, will be given as follows [51, 52]:

$$
\Delta N=\frac{\chi_{\mathrm{N} 80}-\chi_{\mathrm{inh}}}{2\left(\eta_{\mathrm{N} 80}+\eta_{\mathrm{inh}}\right)} .
$$

In order to calculate the fraction of electrons transferred, a theoretical value for the absolute electronegativity of N80 according to Pearson was used $\chi_{\mathrm{N} 80}=463.1 \mathrm{~kJ} \cdot \mathrm{mol}^{-1}$ and $\mathrm{a}$ global hardness of $\eta_{\mathrm{N} 80}=0$, by assuming that the Fe atoms are softer than the neutral metallic atoms.

The global hardness, $\eta$, is a parameter that gives paramount information concerning the reactive behavior of the molecule. The values of $\eta$ for TU and HMTA are 216.3 and $287.9 \mathrm{~kJ} \cdot \mathrm{mol}^{-1}$, respectively. Therefore, the calculated reactivity order for the derivatives in aqueous phase inhibitors is TU $>$ HMTA.

$\Delta N$ is the fraction of electrons transferred from inhibitor to the N80 surface. The values of $\Delta N$ manifested inhibition effect resulted from electrons donation. If $\Delta N<3.6$, the inhibition efficiency would improve with increasing electron donating ability at the metal surface [53]. From Table 4, it can be concluded that TU and HMTA have greater ability of electrons donation to formed inhibitive adsorption layer.

3.5. Molecular Dynamics Analysis. The adsorption structures of TU and HMTA on N80 (1 111 ) surface were constructed using molecular dynamics simulation. The possibility of their 


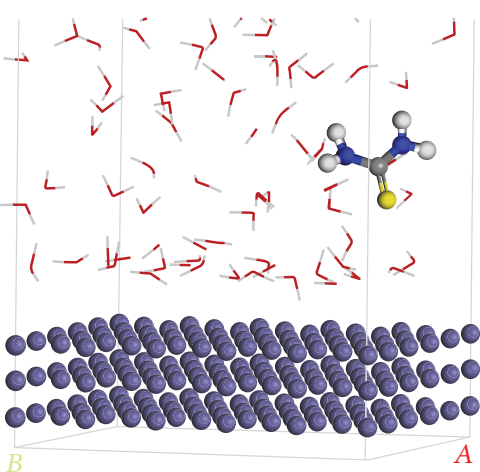

(a) $\mathrm{TU}$

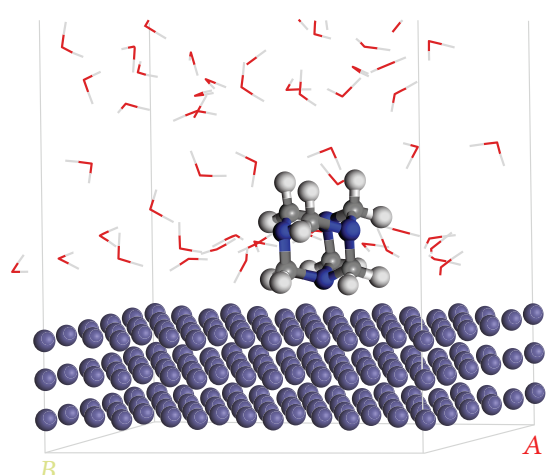

(b) HMTA

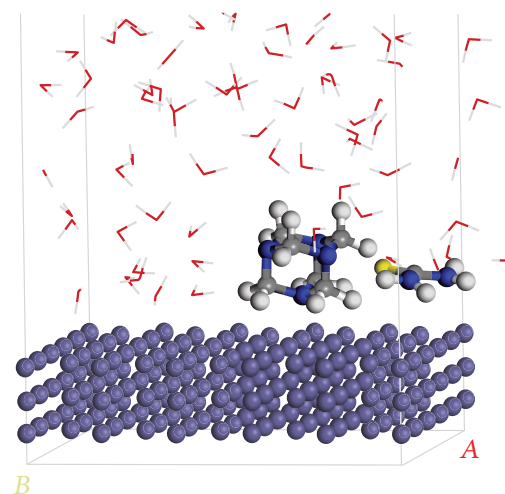

(c) TU + HMTA

FIgURE 8: Mode of adsorption of inhibitors on the Fe (111) surface at $25 \pm 1^{\circ} \mathrm{C}$ : (a) TU, (b) HMTA, and (c) TU + HMTA.

adsorption on the N80 (llll) surface was simulated as in Figure 8.

Figure 8 shows the equilibrium configuration of the inhibitors. It can be seen that the adsorption occurred through the nitrogen atom for TU and the distance between surface and TU is long. For HMTA, there are no preferential directions for adsorption and the distance between surface and HMTA is small. For a combination of TU and HMTA, it can be seen that the adsorption of HMTA is not greatly changed. However, the TU molecules move closer to the N80 surface and the locations of adsorption on the N80 surface are changed into nitrogen and sulfur due to the interaction between TU and HMTA.

The corresponding interaction energies between the N80 surface and the inhibitor molecules were calculated and are listed in Table 5.

The interaction energy is the key parameter to evaluate the inhibition performance. The interaction energies obtained are $-69.911 \mathrm{~kJ} \cdot \mathrm{mol}^{-1},-126.302 \mathrm{~kJ} \cdot \mathrm{mol}^{-1}$, and $-132.352 \mathrm{~kJ} \cdot \mathrm{mol}^{-1}$ for different cases. It can be seen that the interaction energy between N80 (lll 111$)$ surface and TU is small, which is in agreement with the previous adsorption results. Furthermore, the combination of TU and HMTA will increase the interaction energy between N80 (1 111$)$ surface and inhibitors.

Diffusion coefficients can be used to quantitatively describe the diffusion ability of corrosion medium particles in the corrosion inhibitor film. The smaller the corrosive medium particles of diffusion coefficient are, the better the performances of the corrosion inhibitor film are. The diffusion coefficient $(D)$ of the corrosive particles can be obtained through the Einstein relation as follows:

$$
\begin{aligned}
D & =\frac{1}{6 N_{a}} \lim _{t \rightarrow \infty} \frac{d}{d t} \sum_{i}^{N_{a}}\left\langle\left[r_{i}(t)-r_{i}\left(t_{0}\right)\right]^{2}\right\rangle \\
& =\frac{1}{6 N_{a}} \lim _{t \rightarrow \infty} \frac{d}{d t} \sum_{i}^{N_{a}} \mathrm{MSD}=\frac{a}{6} .
\end{aligned}
$$

$N_{a}$ is the number of diffusion atoms in the system, $r_{i}(t)$ and $r_{i}\left(t_{0}\right)$ represent the location of inhibitors molecule or

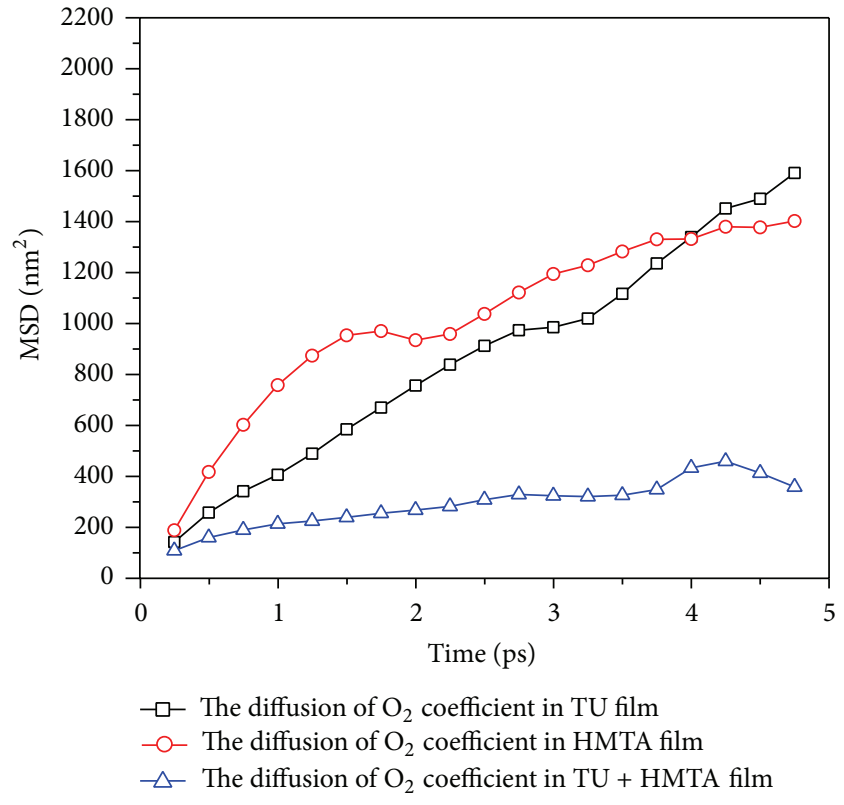

FIgURE 9: The diffusion coefficient $(D)$ of oxygen in three inhibitors film at $25 \pm 1^{\circ} \mathrm{C}$.

particle in $t$ and initial time, and $a$ represents the curve slope of mean square displacement (MSD) to time. The diffusion coefficient can be obtained using (13) in the different corrosion inhibitors, as shown in Figures 9 and 10.

It can be seen from Figure 9 that the diffusion coefficients of oxygen greatly decrease if both TU and HMTA are added to the solution and it can be concluded that a more stable film will form in this case, which has been also verified by previous cathodic polarization curves. Furthermore, Figure 10 indicates that the self-diffusion coefficients are $2.437 \times 10^{-7} \mathrm{~m}^{2} \cdot \mathrm{s}^{-1}, 8.496 \times 10^{-7} \mathrm{~m}^{2} \cdot \mathrm{s}^{-1}$, and $1.145 \times$ $10^{-8} \mathrm{~m}^{2} \cdot \mathrm{s}^{-1}$ for TU, HMTA, and the combination of TU and HMTA at $25 \pm 1^{\circ} \mathrm{C}$, respectively. It can be seen that the selfdiffusion coefficients greatly decrease if both TU and HMTA are added to the solution and it can be concluded that a more stable film will form in this case. 
TABLE 5: Interaction and binding energy of the benzotriazole derivatives on N80 (lll 111$)$ surface at $25 \pm 1^{\circ} \mathrm{C}$.

\begin{tabular}{lccccc}
\hline Inhibitors & $E_{\text {total }} / \mathrm{kJ} \mathrm{mol}^{-1}$ & $E_{\text {surface }} / \mathrm{kJ} \mathrm{mol}^{-1}$ & $E_{\text {initi }} / \mathrm{kJ} \mathrm{mol}^{-1}$ & Interaction energy $/ \mathrm{kJ} \mathrm{mol}^{-1}$ & Binding energy $/ \mathrm{kJ} \mathrm{mol}^{-1}$ \\
\hline TU & 7383.014504 & 7572.479812 & -119.554346 & -69.911 & 69.911 \\
HMTA & 6101.689515 & 6818.939516 & -590.948316 & -126.302 & 126.302 \\
TU + HMTA & 5441.742410 & 6012.418128 & -438.324184 & -132.352 & 132.352 \\
\hline
\end{tabular}

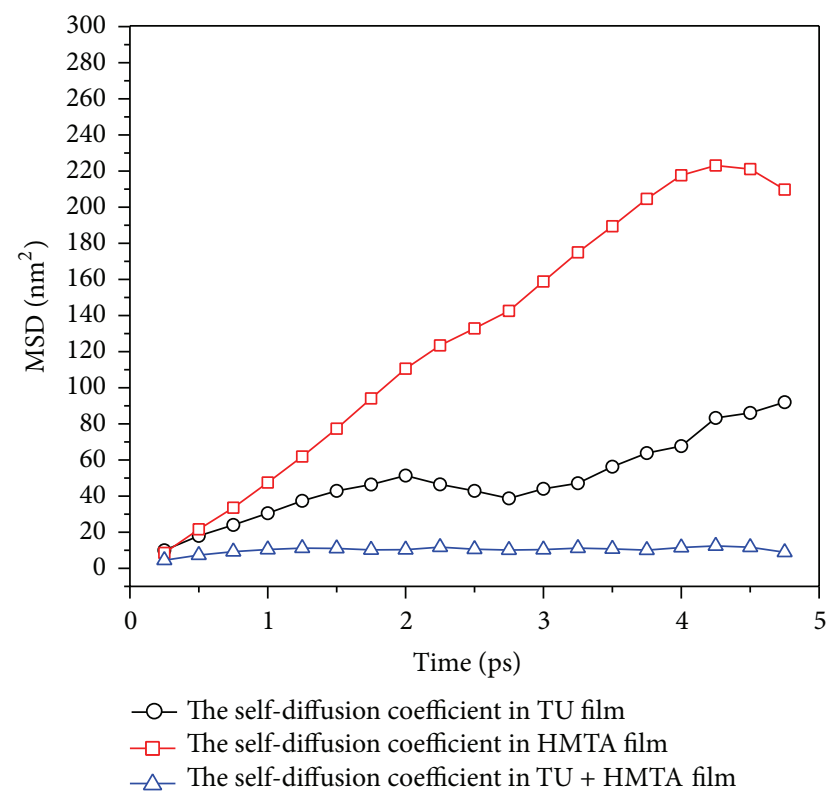

FIgURE 10: The self-diffusion coefficient $(D)$ in three inhibitors film at $25 \pm 1^{\circ} \mathrm{C}$.

3.6. Inhibition Mechanism. Generally, two types of inhibition mechanism were proposed. One was the formation of polymeric complexes with N80 ions depending on the applied conditions [54]. Another was forming a protective film on the N80 surface. Based on the above analysis, it can be determined that the inhibition mechanism of this inhibitor is the second one. The dynamic process of the formation of the protective film can be described as follows. When the inhibitors are added to the solution, the reactive metal surface will change to the passive state due to the adsorption of the inhibitor molecules on the surface. The adsorption can be described mainly by chemisorption, which will occur through the $\mathrm{N}$ and $\mathrm{S}$ of TU and HMTA due to its inherent electron donor ability.

TU has inherent electron donor ability to the metal surface due to the lower $\Delta E$ and $\eta$ values; it also strongly interacts with the water molecules in the solution. Because it is a polar molecule with $\mu=3.545$, the interaction energy between metal surface and TU is only $69.911 \mathrm{~kJ} \cdot \mathrm{mol}^{-1}$. The case is the opposite for HMTA. Although HMTA has a smaller inherent electron donor ability to the metal surface than TU, it has repulsive effects on the water molecules because it is a nonpolar molecule with $\mu=0.014$. Combining the two of them not only enhances the films integrity, but also increases the resistance against diffusion of oxygen molecules from the solution to the N80 surface.

\section{Conclusions}

In this paper, the combined use of TU and HMTA as corrosion inhibitors for $\mathrm{N} 80$ surfaces in $15 \% \mathrm{HCl}$ solution was systematically investigated by electrochemical experiments and quantum chemical calculations. The main conclusions can be summarized as follows.

(1) The results of SEM-EDX analysis manifested that the presence of inhibitors TU and HMTA in appropriate concentration was able to detect protective film on the surface of N80 samples and reduce the damage of chloride ions in comparison to the samples without inhibitors.

(2) The combined use of TU and HMTA in $15 \% \mathrm{HCl}$ solution yields an excellent corrosion inhibition effect, regarding cathodic reactions in a hydrochloric acid solution. The highest observed inhibition efficiency was $95.56 \%$.

(3) The adsorption of the mixture on the N80 surface can be described by the Langmuir isotherm, the highest surface coverage is 0.981 , and the free energy of adsorption is $-35.50 \mathrm{~kJ} \cdot \mathrm{mol}^{-1}$. The inhibition mechanism of the inhibitors includes the formation of a protective film on the N80 surface mainly due to chemisorption. The protective film will reduce the diffusion coefficients of corrosive particles.

\section{Conflict of Interests}

The authors declare that there is no conflict of interests regarding the publication of this paper.

\section{Acknowledgments}

The financial supports from the National Natural Science Foundation of China (no. 51301132), Specialized Research Fund for the Doctoral Program of Higher Education (no. 20136101120009), Chinese Postdoctoral Science Foundation (2014M550507), and Shaanxi Technology Committee Industrial Public Relation Project (2014K08-28) are greatly acknowledged. This research project was supported by Central for High Performance Computing of Northwestern Polytechnical University, China.

\section{References}

[1] M. Chevalier, F. Robert, N. Amusant, M. Traisnel, C. Roos, and M. Lebrini, "Enhanced corrosion resistance of mild steel in $1 \mathrm{M}$ hydrochloric acid solution by alkaloids extract from 
Aniba rosaeodora plant: electrochemical, phytochemical and XPS studies," Electrochimica Acta, vol. 131, pp. 96-105, 2014.

[2] G. Gunasekaran and L. R. Chauhan, "Eco friendly inhibitor for corrosion inhibition of mild steel in phosphoric acid medium," Electrochimica Acta, vol. 49, no. 25, pp. 4387-4395, 2004.

[3] X. Jiang, Y. G. Zheng, and W. Ke, "Corrosion inhibitor performances for carbon dioxide corrosion of N80 steel under static and flowing conditions," Corrosion, vol. 61, no. 4, pp. 326-334, 2005.

[4] J. Zhang, X.-L. Gong, H.-H. Yu, and M. Du, "Inhibition behavior of imidazoline phosphate compound inhibitor on Q235 steel in hydrochloric acid medium," Corrosion, vol. 67, no. 4, pp. 0450051-0450057, 2011.

[5] R. De Marco, W. Durnie, A. Jefferson, B. Kinsella, and A. Crawford, "Persistence of carbon dioxide corrosion inhibitors," Corrosion, vol. 58, no. 4, pp. 354-363, 2002.

[6] A. L. D. Q. Baddini, S. P. Cardoso, E. Hollauer, and J. A. D. C. P. Gomes, "Statistical analysis of a corrosion inhibitor family on three steel surfaces (duplex, super-13 and carbon) in hydrochloric acid solutions," Electrochimica Acta, vol. 53, no. 2, pp. 434-446, 2007.

[7] M. A. Quraishi and D. Jamal, "Fatty acid triazoles: novel corrosion inhibitors for oil well steel (N-80) and mild steel," Journal of the American Oil Chemists' Society, vol. 77, no. 10, pp. 1107-1111, 2000.

[8] G. Cabello, G. P. Funkhouser, J. Cassidy, C. E. Kiser, J. Lane, and A. Cuesta, "CO and trans-cinnamaldehyde as corrosion inhibitors of I825, L80-13Cr and N80 alloys in concentrated $\mathrm{HCl}$ solutions at high pressure and temperature," Electrochimica Acta, vol. 97, pp. 1-9, 2013.

[9] M. Finšgar and J. Jackson, "Application of corrosion inhibitors for steels in acidic media for the oil and gas industry: a review," Corrosion Science, vol. 86, pp. 17-41, 2014.

[10] G. Golestani, M. Shahidi, and D. Ghazanfari, "Electrochemical evaluation of antibacterial drugs as environment-friendly inhibitors for corrosion of carbon steel in $\mathrm{HCl}$ solution," Applied Surface Science, vol. 308, pp. 347-362, 2014.

[11] B. Jeragh and A. A. El-Asmy, "Coordination of Fe(III), Co(II), $\mathrm{Ni}(\mathrm{II}), \mathrm{Cu}(\mathrm{II}), \mathrm{Zn}(\mathrm{II}), \mathrm{Cd}(\mathrm{II}), \mathrm{Hg}(\mathrm{II}), \mathrm{Pd}(\mathrm{II})$ and $\mathrm{Pt}(\mathrm{II})$ with 2,5-hexanedione bis(thiosemicarbazone), HBTS: crystal structure of cis-[Pd(HBTS) $] \mathrm{Cl}_{2}$ and 1-(2,5-dimethyl-1H-pyrrol-yl)thiourea," Spectrochimica Acta. Part A. Molecular and Biomolecular Spectroscopy, vol. 130, pp. 546-552, 2014.

[12] V. V. Torres, V. A. Rayol, M. Magalhães et al., "Study of thioureas derivatives synthesized from a green route as corrosion inhibitors for mild steel in $\mathrm{HCl}$ solution," Corrosion Science, vol. 79, pp. 108-118, 2014.

[13] G. M. Brown, G. A. Hope, D. P. Schweinsberg, and P. M. Fredericks, "SERS study of the interaction of thiourea with a copper electrode in sulphuric acid solution," Journal of Electroanalytical Chemistry, vol. 380, no. 1-2, pp. 161-166, 1995.

[14] V. Grozovski, H. Kasuk, S. Kallip, and E. Lust, "Adsorption of thiourea on $\mathrm{Bi}(111)$ electrode surface," Journal of Electroanalytical Chemistry, vol. 712, pp. 103-112, 2014.

[15] B. H. Loo, "Molecular orientation of thiourea chemisorbed on copper and silver surfaces," Chemical Physics Letters, vol. 89, no. 4, pp. 346-350, 1982.

[16] S. Hong, W. Chen, Y. Zhang, H. Q. Luo, M. Li, and N. B. Li, "Investigation of the inhibition effect of trithiocyanuric acid on corrosion of copper in 3.0wt.\% NaCl," Corrosion Science, vol. 66, pp. 308-314, 2013.
[17] X. Liu, G. S. Frankel, B. Zoofan, and S. I. Rokhlin, "Effect of applied tensile stress on intergranular corrosion of AA2024-T3," Corrosion Science, vol. 46, no. 2, pp. 405-425, 2004.

[18] M. Iannuzzi and G. S. Frankel, "Mechanisms of corrosion inhibition of AA2024-T3 by vanadates," Corrosion Science, vol. 49, no. 5, pp. 2371-2391, 2007.

[19] D. H. Nam, R. H. Kim, D. W. Han, J. H. Kim, and H. S. Kwon, "Effects of $\left(\mathrm{NH}_{4}\right)_{2} \mathrm{SO}_{4}$ and BTA on the nanostructure of copper foam prepared by electrodeposition," Electrochimica Acta, vol. 56, no. 25, pp. 9397-9405, 2011.

[20] A. G. Brolo, M. L. A. Temperini, and S. M. L. Agostinho, "Copper dissolution in bromide medium in the absence and presence of hexamethylenetetramine (HMTA)," Electrochimica Acta, vol. 44, no. 4, pp. 559-571, 1998.

[21] J. Vosta, J. Eliasek, and P. Knizek, "A quantum-chemical study of the corrosion inhibition of iron by means of aniline derivatives in hydrochloric acid," Corrosion, vol. 32, no. 5, pp. 183-187, 1976.

[22] M. A. Amin, K. F. Khaled, Q. Mohsen, and H. A. Arida, "A study of the inhibition of iron corrosion in $\mathrm{HCl}$ solutions by some amino acids," Corrosion Science, vol. 52, no. 5, pp. 1684-1695, 2010.

[23] Y. Tang, X. Yang, W. Yang, R. Wan, Y. Chen, and X. Yin, "A preliminary investigation of corrosion inhibition of mild steel in $0.5 \mathrm{M} \mathrm{H}_{2} \mathrm{SO}_{4}$ by 2-amino-5-(n-pyridyl)-1,3,4-thiadiazole: polarization, EIS and molecular dynamics simulations," Corrosion Science, vol. 52, no. 5, pp. 1801-1808, 2010.

[24] Y. Tang, X. Yang, W. Yang, Y. Chen, and R. Wan, "Experimental and molecular dynamics studies on corrosion inhibition of mild steel by 2-amino-5-phenyl-1,3,4-thiadiazole," Corrosion Science, vol. 52, no. 1, pp. 242-249, 2010.

[25] C. Soontrapa and Y. Chen, "Molecular dynamics potentials in magnetite $\left(\mathrm{Fe}_{3} \mathrm{O}_{4}\right)$ modeling," Computational Materials Science, vol. 50, no. 12, pp. 3271-3281, 2011.

[26] S. M. A. Hosseini, M. Salari, E. Jamalizadeh, and A. H. Jafari, "Electrochemical and quantum chemical studies of aromatic amines on the steel corrosion in acid solution," Corrosion, vol. 68, no. 7, pp. 600-609, 2012.

[27] L. S. Živković, J. P. Popić, B. V. Jegdić, Z. Dohčević-Mitrović, J. B. Bajat, and V. B. Miškovic-Stankovic, "Corrosion study of ceria coatings on AA6060 aluminum alloy obtained by cathodic electrodeposition: effect of deposition potential," Surface and Coatings Technology, vol. 240, pp. 327-335, 2014.

[28] N. Priyantha, P. Jayaweera, and D. D. Macdonald, "An electrochemical impedance study of Alloy 22 in $\mathrm{NaCl}$ brine at elevated temperature. I. Corrosion behavior," Journal of Electroanalytical Chemistry, vol. 572, pp. 409-419, 2004.

[29] S. Ranganatha, T. V. Venkatesha, K. Vathsala, and M. K. P. Kumar, "Electrochemical studies on $\mathrm{Zn} /$ nano- $\mathrm{CeO}_{2}$ electrodeposited composite coatings," Surface and Coatings Technology, vol. 208, pp. 64-72, 2012.

[30] X. Li, J. Wang, E.-H. Han, and W. Ke, "Corrosion behavior for Alloy 690 and Alloy 800 tubes in simulated primary water," Corrosion Science, vol. 67, pp. 169-178, 2013.

[31] J. Hu, Q. Duan, G. Cheng, Z. Zhang, X. Chen, and B. Wang, "Investigation of the impedance characteristics in the pitting evolutionary process of Alloy 690," Annals of Nuclear Energy, vol. 58, pp. 25-32, 2013.

[32] T. Tüken, B. Yazici, and M. Erbil, "The use of polyindole for prevention of copper corrosion," Surface and Coatings Technology, vol. 200, no. 16-17, pp. 4802-4809, 2006. 
[33] S. Skale, V. Doleček, and M. Slemnik, "Substitution of the constant phase element by Warburg impedance for protective coatings," Corrosion Science, vol. 49, no. 3, pp. 1045-1055, 2007.

[34] M. Behpour and N. Mohammadi, "Investigation of inhibition properties of aromatic thiol self-assembled monolayer for corrosion protection," Corrosion Science, vol. 65, pp. 331-339, 2012.

[35] Q. Q. Shu, P. J. Love, A. Bayman, and P. K. Hansma, "Aluminum corrosion: correlations of corrosion rate with surface coverage and tunneling spectra of organic inhibitors," Applications of Surface Science, vol. 13, no. 3-4, pp. 374-388, 1982.

[36] P. Singh, K. Bhrara, and G. Singh, "Adsorption and kinetic studies of L-leucine as an inhibitor on mild steel in acidic media," Applied Surface Science, vol. 254, no. 18, pp. 5927-5935, 2008.

[37] A. O. Yüce and G. Kardaş, "Adsorption and inhibition effect of 2-thiohydantoin on mild steel corrosion in $0.1 \mathrm{M} \mathrm{HCl}$," Corrosion Science, vol. 58, pp. 86-94, 2012.

[38] D. Daoud, T. Douadi, S. Issaadi, and S. Chafaa, "Adsorption and corrosion inhibition of new synthesized thiophene Schiff base on mild steel $\mathrm{X} 52$ in $\mathrm{HCl}$ and $\mathrm{H}_{2} \mathrm{SO}_{4}$ solutions," Corrosion Science, vol. 79, pp. 50-58, 2014.

[39] E. Geler and D. S. Azambuja, "Corrosion inhibition of copper in chloride solutions by pyrazole," Corrosion Science, vol. 42, no. 4 , pp. 631-643, 2000.

[40] I. B. Obot, E. E. Ebenso, and M. M. Kabanda, "Metronidazole as environmentally safe corrosion inhibitor for mild steel in $0.5 \mathrm{M} \mathrm{HCl}$ : experimental and theoretical investigation," Journal of Environmental Chemical Engineering, vol. 1, no. 3, pp. 431-439, 2013.

[41] M. Z. A. Rafiquee, N. Saxena, S. Khan, and M. A. Quraishi, "Influence of surfactants on the corrosion inhibition behaviour of 2-aminophenyl-5-mercapto-1-oxa-3,4-diazole (AMOD) on mild steel," Materials Chemistry and Physics, vol. 107, no. 2-3, pp. 528-533, 2008.

[42] A. Sivanesan and S. A. John, "Adsorption thermodynamics and kinetics study for the self-assembly of 1,8,15,22tetraaminophthalocyanatocobalt(II) on glassy carbon surface," Electrochimica Acta, vol. 54, no. 28, pp. 7458-7463, 2009.

[43] E. Machnikova, K. H. Whitmire, and N. Hackerman, "Corrosion inhibition of carbon steel in hydrochloric acid by furan derivatives," Electrochimica Acta, vol. 53, no. 20, pp. 6024-6032, 2008.

[44] A. Ouchrif, M. Zegmout, B. Hammouti, S. El-Kadiri, and A. Ramdani, "1,3-Bis(3-hyroxymethyl-5-methyl-1-pyrazole) propane as corrosion inhibitor for steel in $0.5 \mathrm{M} \mathrm{H}_{2} \mathrm{SO}_{4}$ solution," Applied Surface Science, vol. 252, no. 2, pp. 339-344, 2005.

[45] F. Bentiss, M. Lagrenée, B. Elmehdi, B. Mernari, M. Traisnel, and $\mathrm{H}$. Vezin, "Electrochemical and quantum chemical studies of 3,5-Di (n-Tolyl)-4-amino-1,2,4-triazole adsorption on mild steel in acidic media," Corrosion, vol. 58, no. 5, pp. 399-407, 2002.

[46] I. Lukovits, E. Kálmán, and F. Zucchi, "Corrosion inhibitorscorrelation between electronic structure and efficiency," Corrosion, vol. 57, no. 1, pp. 3-8, 2001.

[47] K. F. Khaled, "Corrosion control of copper in nitric acid solutions using some amino acids-a combined experimental and theoretical study," Corrosion Science, vol. 52, no. 10, pp. 3225-3234, 2010

[48] S. Zor, M. Saracoglu, F. Kandemirli, and T. Arslan, "Inhibition effects of amides on the corrosion of copper in $1.0 \mathrm{M} \mathrm{HCl}$ : theoretical and experimental studies," Corrosion, vol. 67, no. 12 , Article ID 125003, pp. 125003-1-125003-11, 2011.

[49] L. A. F. Costa, H. S. Breyer, and J. C. Rubim, "Surface-enhanced Raman scattering (SERS) on copper electrodes in 1- $n$-butyl-3methylimidazoliun tetrafluorbarate (BMI.BF4): the adsorption of benzotriazole (BTAH)," Vibrational Spectroscopy, vol. 54, no. 2, pp. 103-106, 2010.

[50] D. Gelman, D. Starosvetsky, and Y. Ein-Eli, "Copper corrosion mitigation by binary inhibitor compositions of potassium sorbate and benzotriazole," Corrosion Science, vol. 82, pp. 271279, 2014.

[51] A. Döner, R. Solmaz, M. Özcan, and G. Kardaş, "Experimental and theoretical studies of thiazoles as corrosion inhibitors for mild steel in sulphuric acid solution," Corrosion Science, vol. 53, no. 9, pp. 2902-2913, 2011.

[52] V. S. Sastri and J. R. Perumareddi, "Molecular orbital theoretical studies of some organic corrosion inhibitors," Corrosion, vol. 53, no. 8, pp. 617-622, 1997.

[53] H. Ju, Z.-P. Kai, and Y. Li, "Aminic nitrogen-bearing polydentate Schiff base compounds as corrosion inhibitors for iron in acidic media: a quantum chemical calculation," Corrosion Science, vol. 50, no. 3, pp. 865-871, 2008.

[54] K. F. Khaled, S. A. Fadl-Allah, and B. Hammouti, "Some benzotriazole derivatives as corrosion inhibitors for copper in acidic medium: experimental and quantum chemical molecular dynamics approach," Materials Chemistry and Physics, vol. 117, no. 1, pp. 148-155, 2009. 

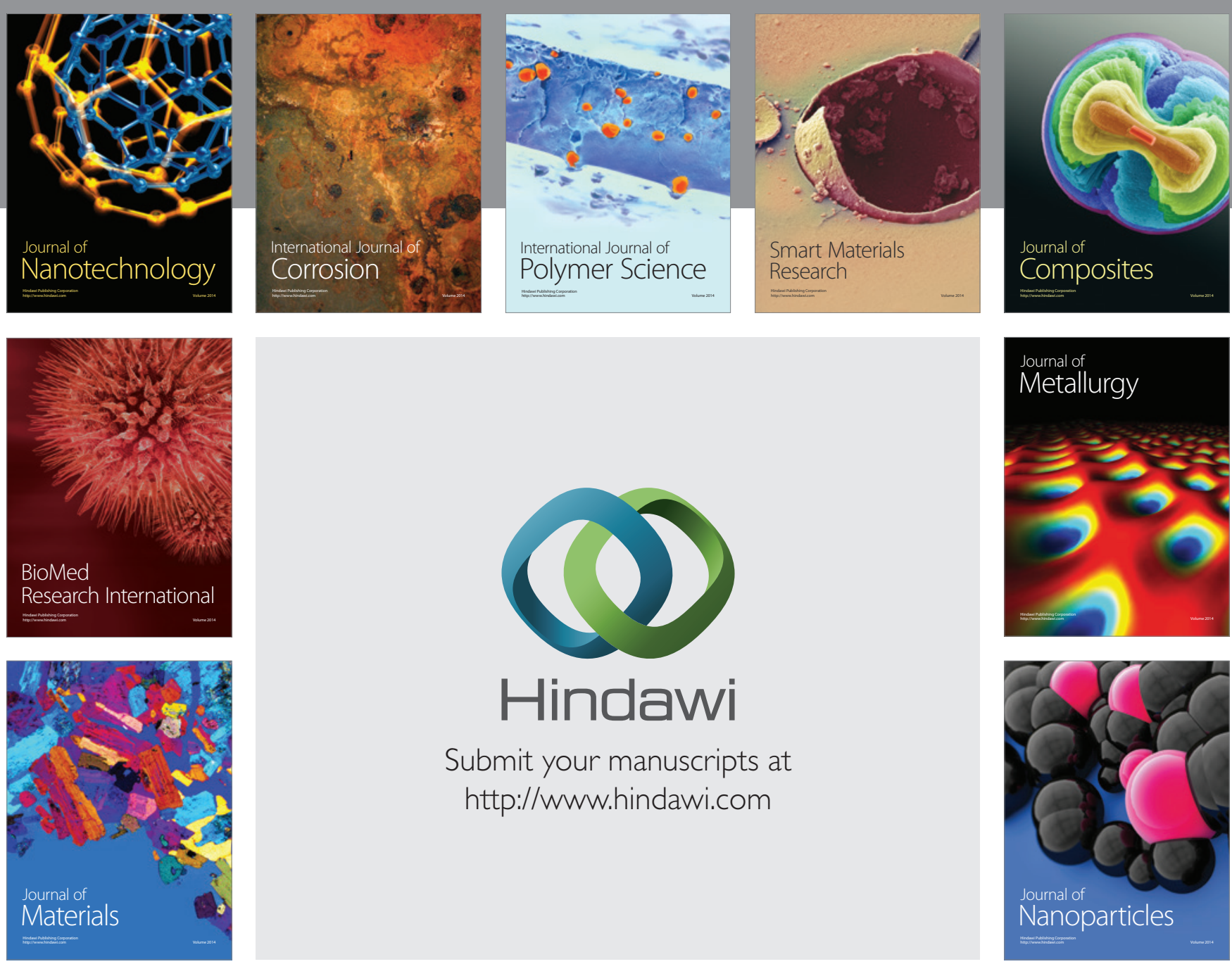

Submit your manuscripts at http://www.hindawi.com
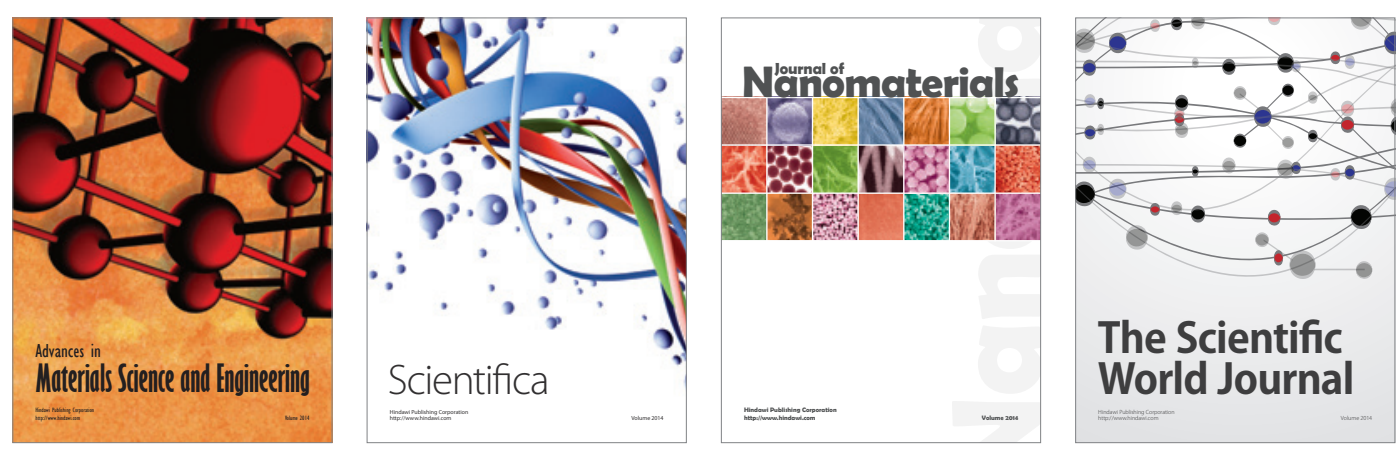

\section{The Scientific World Journal}
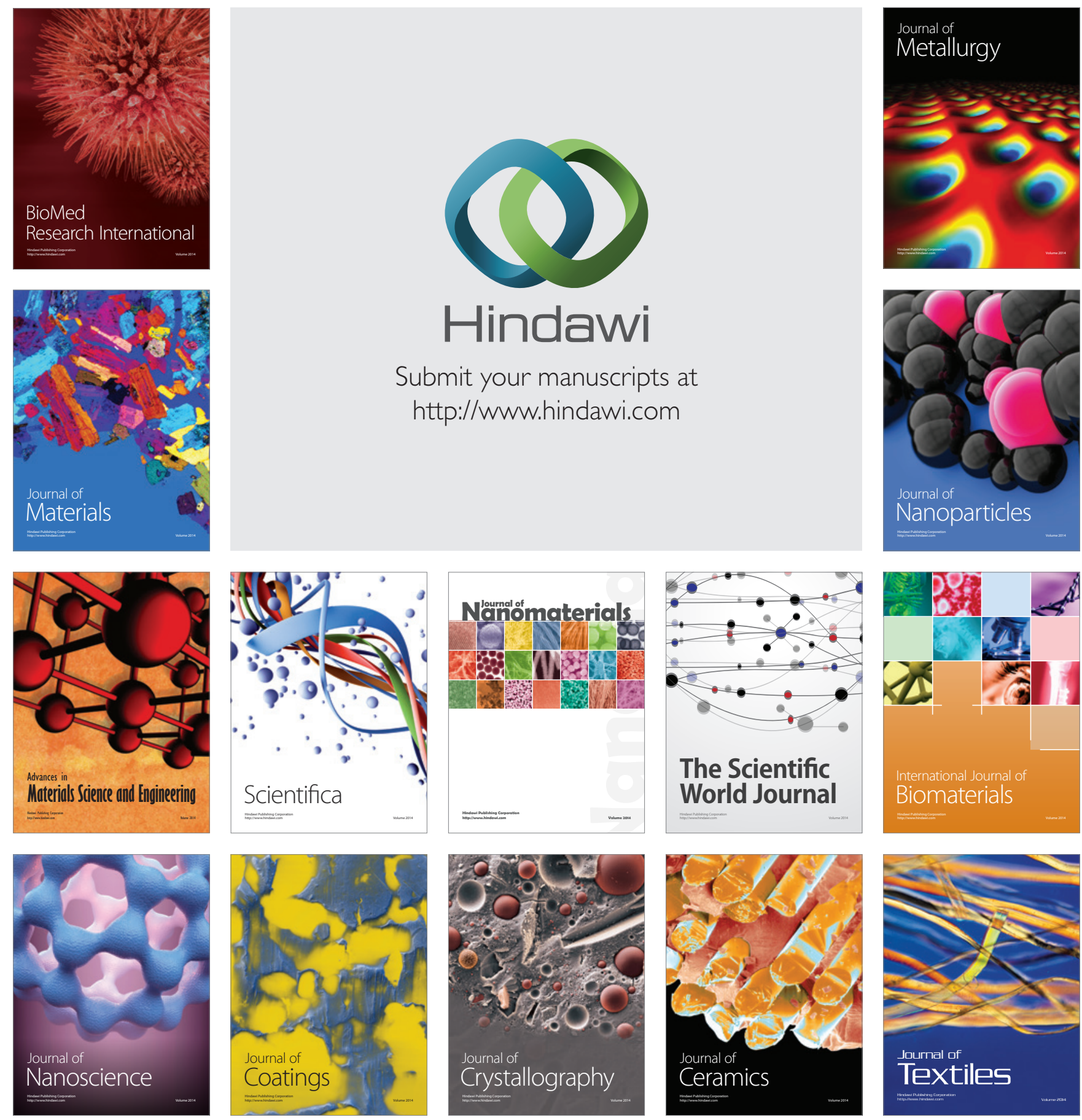